Paweł Raja (Wroclaw University of Economics)

\title{
Institutional Changes in Malaysia. New dimensions of challenges after the global financial crisis
}

\section{Introduction}

In regards to the recent economic crisis, one can perceive the global economy as a multi-linked structure. Therefore, one has to concern the importance of international relations as a science and find a new theoretical approach to understand new processes. As this approach comes from theoretical considerations in order to predict future events, the origin of this approach comes from real-life actions. The complexity of the financial crisis brings attention to the informal institutions, which are either difficult to measure or rationally explained. However, on the basis of non-material forms of capital, one can name some of the cultural determinants which could help explain the rapid changes. Within the framework of New Institutional Economics the author puts pressure on the neoclassical model of development and the concept of homo economicus in favor of cultural determinants. From this perspective the author tries to point out the need for institutional change and to analyze individual pursuits of economic welfare in a heterogeneous society where social capital and foremost trust come to the forefront. Simultaneously, while identifying informal institutions indirectly impacting economic changes, the author brings to attention the new dimensions of challenges, which are focused on the need for formal changes in the private and public sectors. The field of study concerns Malaysia, as from the author's perspective it is a country that successfully eases social tensions in favor of constant development.

Therefore, the author is fully aware of the number of issues to discuss; however, it proves the complexity as well as the integrity of the problem. To understand the process of institutional changes the author emphasizes the whole problem of institutional reforms. (Picture 1) Hence, the potential research program is defined as: institutional change and new dimensions of challenges after the global financial crisis within the framework of New Institutional Economics. Scientific problems can be divided into groups concerning: formal and informal institutions, property rights, socio-political integration, as well as regional responsibility to retain economic order. 


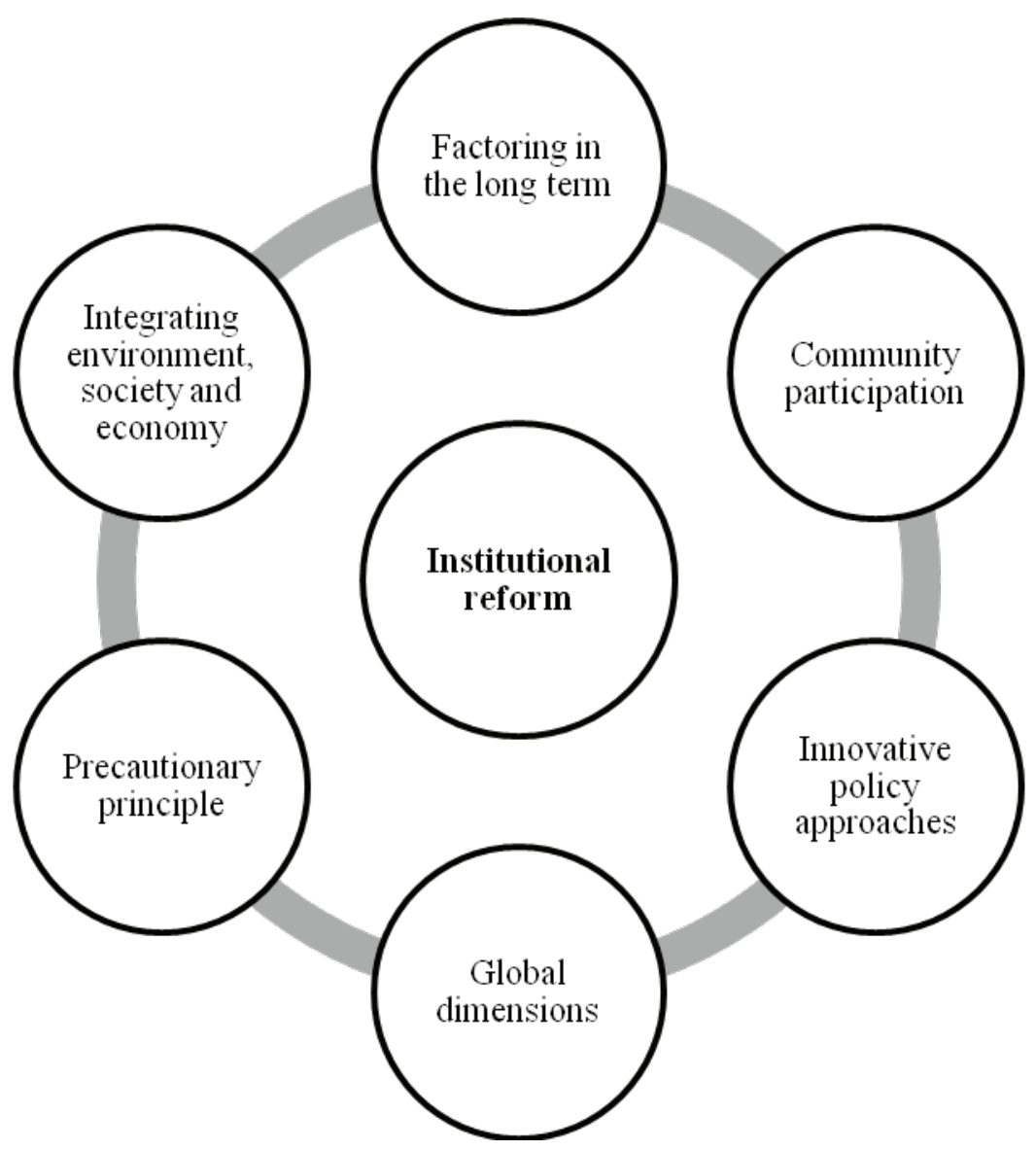

Picture 1. Institutional reforms

Source: Own work based on Hezri, 2011

Different growth rates across the countries can be analyzed by either the different levels of capital accumulation or by the possibilities of free international trade. Thus capital accumulation can be defined by the human (and social) capital, as well as material goods. At this point, however, the export growth could explain either higher or lower growth rates, one looks at the import side. According to the neoclassical model of development, institutions play their role in liberalization, privatization (as in the case of Malaysia) or changes in law. Besides that, neoclassical economists do not pay enough attention on informal institutions and do not perceive cultural determinants as important for the growth rate. In regards to New Institutional Economics, socioeconomic challenges should be expressed both by formal and informal institutions and this form could be a base for any further explanations in favor of economic (financial) crises. 
Major questions to be asked could follow: What level of responsibility has been given to this heterogeneous country throughout the last couple of years? Could the performance of the government present an example of efficient work and pressure on economic development or should one focus on sustainable development to answer the international (and national) expectations?, and what elements of mutual understanding should be improved?

To define institutions is to recognize them as organizations. Those organizations refer to banks, financial companies and any others that are similar concerning any form of securities. According to Douglas North, institutions can also be understood as rules, which might acquire different meanings and could be enforced by the law or/and the local cultural background. In spite of that, one is able to see two kinds of institutions - implemented and enforced by the government and those influenced by the ability to adjust into an informal framework. Then informal institutions are enforced by society and cannot be disconnected from any broader analysis of the economic performance of a country. In the case of Malaysia, a heterogeneous country where any individual pursuit of economic welfare and possibilities given at the start (through the education system, scholarships, informal constraints) have already been defined, brings with it a new dimension of challenges. Thus it puts pressure on sociopolitical integration, divides human actions from pragmatic to opportunistic and shapes values. In this sense an individual is already aware what is right and wrong, what is just and unjust, easy to gain or requires hard work. Therefore, culture is a complex and multi-linked structure, shaping the required abilities to perform and adjust to expected challenges. In this context the author claims that any institutional change (and long-term development) is a matter of social and cultural acceptance of the common pursuit for a sustainable economy and an improvement on the quality of life. Both culture and institutions influence the economic performance of a country. Therefore they determine (Kunio, 2004):

- The degree of economic freedom;

- The degree to which property rights are protected;

- Level of restrictions;

- Common understanding to what is just and unjust;

- Mutual obligations;

- Level of social tension and the actions to ease them;

- Acceptance to rules of law;

- Foreign countries' perspective on international trade possibilities (import and export rates).

Over the years Malaysia has witnessed a tremendous growth rate - double digits during the 1970s, 1980s, 1990s (till 1997) and throughout the last ten years. However, it has also been impacted by some major financial downturns, which in turn bring attention to the concept of regional stability and common responsibility 
to retain financial order in the region. This is due to the economies of SouthEastern Asian countries being to some extent connected and work on the regional level could improve its resistance to further downturns. (Malaysia presented an initiative to form ASEAN) What role in those regional pacts has been given to Malaysia? The fact is that Malaysia has not yet fully recovered from the 1997/98 financial crisis. Other countries in the region have attracted more foreign investors and put more pressure on reviving GDP growth, whereas the Malaysian economy depends on international markets. Domestic productivity is growing too slow to retain its importance. A further drop in the Competitiveness Index and the common discouragement of private investments due to the presence of government linked companies lead to a widening of the gap between rich and poor. At the same time the average income is growing slowly and the economic imbalance due to the inter-ethnic policy is still visible. In turn, social capital has been impacted as more highly skilled people choose to work abroad, while the expenditures in the field of Research and Development have also been dropping. Other factors impacting the development rate are commonly defined as an income trap, which negatively result in a low cost advantage as new Asian markets emerge. In this context new reform plans should be presented, pricing systems and broad subsidies should be dropped, patronage and rent seeking should become transparent, and the private sector should focus on investments in $R \& D$ to produce future growth and sustain its competitiveness among other South-Eastern Asian countries. These aims should be qualified as the new pillars of economic development, as change partly depends on the attitude and willingness of the people and not the Malaysian government itself. On the positive side, the global financial crisis, globalization, striving for transparency and the need to compete for talent bring the concept of creative destruction alive. (Schumpeter, 1942).

\section{Domestic effects of the Asian financial crisis}

During the previous financial crisis in the years 1997/98 Malaysia experienced a dramatic slowdown, unexpected due to the positive outcome of the last 50 years of reforms. Aggregate investments (in the private sector) as a share of Malaysian GDP continued to decline. Private investors became stagnant due to the government presence in the economy. Wage growth was highly impacted by the production of low value added goods, which at the beginning made profits. However, in regards to the continuous implementation and some modification of the New Economic Policy, Malaysia has experienced a decline in poverty and small changes in the society. At this point one is able to see the weak institutional framework in which improvement could lead to maintaining the status of being the Asian tiger. 


\subsection{Cultural determinants as informal advantages}

Malaysia is generally an upper-medium income country. In its heterogeneous society one can see the possibilities for Malaysia becoming a hub connecting Europe, the Middle East and the rest of the Asian world. In a country as a whole, this diversity can leverage skills from different ethnic groups and stimulate innovation (endowments could attract wide FPI flow as the country is rich in its diversity of both ethnicity and natural resources). At the same time the diversity of spoken languages and already built international networks generate a positive outcome. It also leads to a better accommodation of new threats as it enhances pragmatism and hard work to adjust to them. If one considers a must for sustainable development, one has to concern the biodiversity and both the chances and threats connected with it. Those natural resources could be used ,in creative and sustainable ways as a base to build new, diverse, high value, high tech industries and services." (New Economic Model for Malaysia, 2010) Renewable energy could stand as one of the examples and the other could be tourism, which is experiencing high growth, while bringing new sources of income and the need for deeper transparency on the international level.

Institutional changes that could bring a shift in the attitude and in the culture could be stated as three complementary programs of reforms. The first of these concerns the income disparity and the need of its reduction through supporting policies, poverty reduction and shifting the focus to the bottom households and entrepreneurs.

The second program deals with the discrimination and the use of transparent measures for change by promoting equal opportunities through the access to health, education and transportation services. Lastly, by building knowledge and awareness through promoting and improving access to higher education (, high skilled studies"), fostering research and development investments (by mutual cooperation between MOE, MOHE and investors) and putting educational pressure on local communities (Sabah, Sarawak). Those initiatives could stand alone unless there is a wish for social and cultural change as it has to bring more awareness of the already chosen path of development by integrating with regional and global markets.

\subsection{Informal institutions and the need for cultural change}

The mutual interaction between a development of an individual (in economic terms) and economic development creates new possibilities to increase welfare. Investing in people is therefore desirable; not as a reason of pressure or the (norms) social environment, but because of its cost effectiveness. However, during the previous financial crisis the Malaysian government had to establish 
a special fund for the poor and low-income groups (The budget for 1998 included a new allocation for the Development Program for the Hardcore Poor). At the same time the government offered micro-credit funds to ,promote income-generating activities and job opportunities were created for the low-income segments of the population, including the most vulnerable groups, through public works." (ISIS, Universiti Malaya 2009) What is more, Malaysia starts to focus on the idea of human development. This is the result of slowly changing informal institutions and the need forsociety to improve their chances and increase individual welfare to gain the advantage and improve theirquality of life. On a national level, especially after the crisis in 2008/2009 and its course, one is able to see a rising awareness of the Malaysian government. It thus provides more employment opportunities, more funding in the educational system, residential programs (please take note at MM2H - Malaysia My Second Home program) or even (including) extended healthcare programs in the regions of Sabah and Sarawak.Althoughlackingasocial protection system, Malaysia has introduced EPF (Employee Provident Fund), a pension program and (SOCSO) an insurance program.

In regards to the Millennium Development Goals (MDG), Malaysia came up with the National Vision Policy. Those goals have been categorized into two possible responses - ESP 1 and ESP 2. One can explain national resilience through ESP 1's following strategies:

Table 1. Assessing the Strategies in ESP 1

\begin{tabular}{|c|l|c|c|c|c|}
\hline & \multicolumn{1}{|c|}{ Thrust } & \multicolumn{1}{|c|}{$\begin{array}{c}\text { Allocation } \\
(\mathrm{RM})\end{array}$} & $\begin{array}{c}\text { Awarded } \\
\text { projects }\end{array}$ & $\begin{array}{c}\text { Completed/Ongoing } \\
\text { projects }\end{array}$ & $\begin{array}{c}\text { Funds disbursed } \\
(\mathrm{RM})\end{array}$ \\
\hline 1 & $\begin{array}{l}\text { Ensuring citizens' } \\
\text { well-being }\end{array}$ & $2,565,000,000$ & 12 & 11 & $1,996,661,000$ \\
\hline 2 & $\begin{array}{l}\text { Developing quality } \\
\text { human capital }\end{array}$ & $960,080,000$ & 12 & 12 & $678,848,000$ \\
\hline 3 & $\begin{array}{l}\text { Strengthening na- } \\
\text { tional resilience }\end{array}$ & $3,281,642,294$ & 25 & 21 & $2,498,722,000$ \\
\hline & Total & $6,806,722,294$ & 49 & 44 & $5,174,231,000$ \\
\hline
\end{tabular}

Source: Own work based on Project Management Unity, Ministry of Finance, Malaysia, 2009

Thus it shows the effort of the government to improve the quality of human capital. Any unused financial resources were as a result of the changing circumstances and the worsening of the global financial situation. Malaysia was not initially hit by the crisis; however, it got it eventually. The second response was to increase employment through development expenditures. 
Table 2. Assessing the Strategies in ESP 2 - Development Expenditure

\begin{tabular}{|c|l|c|c|}
\hline \multicolumn{1}{|c|}{ Thrust } & $\begin{array}{c}\text { Completed/ Ongoing } \\
\text { projects }\end{array}$ & $\begin{array}{c}\text { Funds disbursed } \\
\text { (RM) }\end{array}$ \\
\hline 1 & $\begin{array}{l}\text { Reducing unemployment and increasing employ- } \\
\text { ment opportunities }\end{array}$ & 1 & $8,000,000$ \\
\hline 2 & Assisting the private sector in facing the crisis & 163 & $5,459,825,769$ \\
\hline 3 & Building capacity for the future & 28 & $1,753,705,000$ \\
\hline & Total & 52 & $2,272,500,500$ \\
\hline
\end{tabular}

Source: Own work based on Project Management Unity, Ministry of Finance, Malaysia, 2009.

\section{Formal institutions and the need for changes}

In the case of Malaysia it is a matter of responsibility on both the national and regional levels to retain the economic crisis. According to the New Economic Model for Malaysia, in order to do so one can name hot spots for changes to bring more confidence to investors. The rules for both the public and private sector should be revised. In the public sector the government should focus on policies under the following purposes:

- Reduce friction costs. The main objective of the proposed policy is to create an environment for a "transparent process of government procurement at all levels." (National Economic Advisory Council 2000).

- Improve the decision making processes. Any legal process in Malaysia depends heavily on perspicuous decisions made by the government. This policy aims to create a "responsible" approach for long-term development.

- Modernize the government in terms of human resources. In Malaysia employees face a complicated process of employment based on the racial structure.

- Implement international standards for transparency. As the EU Delegation to Malaysia faces difficulties in dealing with the legal procedures of cooperation, a single entrepreneur might find it accessible, through personal connections, to set up a business and gain profits.

- Empower local entities to perform their duties. Most of the legal processes in Malaysia depend on the individual's perception and their business approach. The Malaysian Industrial Development Authority (MIDA) has currently been implementing a "whole-of-government" approach necessary for the long-term development of the country (Malaysian Rating Corporation Berhad 2010).

In the private sector, the entrepreneurs should be supported by:

- Removing barrier costs and the cost of doing business. TheMalaysian government has introduced the idea of a "one window" policy both for 
encouraging people to set up their own businesses and for creating eportals enabling people to fill in any document online (Mamat, 2010).

- Creating economic systems for entrepreneurship and innovation. The former prime minister of Malaysia strived for an innovative society, where the process of buying new technologies would occasionally reverse. As in the case of the Asian tigers and China, new technologies and new ways of production have been bought from Western countries. By creating a science park, Cyberjaya, TunDr Mahathir Mohammad attracted young people to stay in Malaysia and bring up new ideas (Cyberjaya, Welcoming Newcomers 2012).

- Encouraging efficiency through healthy competition. The most important factor for creating trust between the society and the government is the mutual understanding of the importance of long-term and sustainable development. Through healthy competition and transparent requirements of doing business, Malaysia will sustain its attractiveness for both foreign and internal investments.

- Creating regional champions. This policy aims to improve the quality of regional cooperation, especially in the region of ASEAN. Practice has shown a rapid growth in investments and lower costs of production. One of the most known examples is the Iskandar project in the region of Johor. Where as the main partners are from Malaysia, Singapore and Indonesia, two Polish universities were interested in joining the project.

These actions should be coordinated in order to rebalance the roles of the public and private factors. Firstly, by allowing private companies and small firms to compete with each other and strive for more without this kind of governmental inference that Malaysia is still experiencing. Secondly, reforming and limiting the amount of incentives (any long term development cannot fully rely on incentives as this gives controlled and dependent sources of profitability) andlastly, improving the business environment in order to enhance private investments. In order to ensure sustainable development Malaysia should:

- Preserve natural resources. By supporting green technology and investments in renewable energy Malaysia aims to create a sustainable development. The ongoing debates underline the need to preserve the natural resources for future generations, both in terms of their economic welfare and the requirements of Islam (Khalid 2002).

- Leverage the comparative advantages for high value added productsand services. Malaysia aims to establish an energy policy and new markets for their products. As Malaysia becomes a regional hub for new investments, it will attract international companies with a market of skilled graduates, financial capital and comparatively low wages. (much 
like Poland, Malaysia is an attractive market for, among others, IBM and Hewlett-Packard).

- Meet international requirements. To bring new investments and to sustain its attractiveness Malaysia promotes green technology and the reduction of carbon emissions. The most common example is the Iskandar Project. (Ngah, Tsong, 2011).

- Establish transparent governance. (New Economic Model for Malaysia)By a transparent government, National Economic Advisory Council suggests a partial "liberalization of foreign experts specializing in financial analysis of viability of green technology projects".

\subsection{The Tenth Malaysia Plan and its implications}

Accordingly Malaysia has introduced The Tenth Malaysia Plan for the years 2011-2015; hence one might expect responses to the global financial crisis within the program. It is underlined that the main object is to build an ,inclusive society" whereas the diversity of a society is respected, encouraged (to cooperate) and valued. It underlines the need forcooperation and pragmatism for any change for a better quality of life to take place. Major initiatives through either changes or improvements of formal and informal institutions have been recognized under the NKRA (National Key Result Areas):

- Raising the living standards of low income households. In order to maintain both sustainable development and reduce the potential risk of economic disparities, the Malaysian government promotes labor mobility and creates an open market for low-skilled workers.

- Improving basic rural infrastructure. The foremost important is to improve the education system across rural areas. The author suggests a comprehensive policy that aim sat helping young people receive education in urban areas. This might in the long-term bring new micro-enterprises to life and compete with less diversified big companies.

- Improving student outcomes. By creating a knowledge-based society Malaysia will find its way in the globalizing world and commence to compete with Singapore.

- Improving urban public transport. In the author's view a weak public transport system in Malaysia is more a psychological, than physical concern. The government donates both oil and gas (which increases public spending) and creates new plans of urban development without including public transportation.

- Reducing crime. In Malaysia crime is neglected as an important factor inmaintaining safety. As Malaysia is an Islamic state, the issue of crime is often marginalized. 
- Combating corruption. The policy aimed at reducing corruption focuses mainly onthe costs of doing business. At the same time the private sector (private investments) is often a subject of miscellaneous divagations.

To sustain the growth rate and the process of economic development as a whole Malaysia has to introduce a structural program, where changes are made within formal and informal institutions. What is forefront in a heterogeneous country, where nearly half of the population is to some degree diminished, is to establish an equal participation of women in the economy. As this needs a cultural change it has to be backed up by the government through:

- Higher education attainment and labor force participation. MIDA promotes the autonomy of the Ministry of Higher Education (MOGE), which could "improve the quality of schools". (New Economic Model for Malaysia, 2010)At the same time the Malaysian government sponsors young people to get an education abroad and subsidizes new learning courses (mainly bought from American, Australian and English universities) at domestic universities. This policy aims at expanding the R\&D sector and gives chances for young people for a better life.

- Increasing the number of women in key decision-making positions. Since the independence of Malaysia,women have been denied to take part in the economic development of their country. They have been discouraged from being proactive. However, it has changed. In a heterogeneous country, where pressure on continuous growth is highly visible, women are being brought up to the role of "mitigators" and great entrepreneurs with soft skills. The policy also aims at encouraging both the private and public sectors to employ women and enable them to take part in managerial discussion.

- Eliminating all forms of discrimination. Malaysia is a hub for many societies. Various ethnicities, religions and attitudes create a potential risk of favoring one group and therefore diminishing the other one. However it is an ongoing policy; the Constitution of Malaysia grants Malays the special position to secure their interest. (Please see Article 153 of the Constitution of Malaysia)

- Special assistance schemes to improve entrepreneurship skills. (The Tenth Malaysia Plan, 2010) In the New Economic Model women have been granted a separate discussion. They should expect micro-financing, equal rights, job training, as well as special soft skills couching programs.

To answer how the participation of women can retain the effects of the financial crisis, one could look at other countries in the region like Thailand with the rate of participation of $70 \%$, Singapore with $60.2 \%$ and Indonesia with $51.8 \%$; whereas in Malaysia participation by women stands at just $45.8 \%$. (Economic 
Planning Unit 2008) The development of a country depends on the development of single units; the family is a vital element of a society. Moreover, the improvement in education and limited discrimination gives both women and any household a necessary component of competitiveness and brings more welfare. While increasing the population of women in Malaysia (currently at almost 14 million), more than half of them enroll for a master's degree and then exit the labor force due to family duties and general attitude. Women become a force in the development area and with their multi-tasked roles they improve the abilities to adjust and contribute to the economy.

Table 3. Integrated human capital and talent development framework in Malaysia

\begin{tabular}{|c|c|c|c|c|c|}
\hline $\begin{array}{c}\text { Early } \\
\text { Childhood }\end{array}$ & $\begin{array}{c}\text { Pre- } \\
\text { School }\end{array}$ & $\begin{array}{c}\text { Basic } \\
\text { Education }\end{array}$ & Tertiary Education & Professional & $\begin{array}{c}\text { Retiree/Second } \\
\text { career }\end{array}$ \\
\hline $0+$ & $4+$ & $5+/ 6+$ & $17+$ & \multicolumn{2}{|c|}{$20+$} \\
\hline \multicolumn{3}{|c|}{ Ensuring every child succeeds } & $\begin{array}{l}\text { Mainstreaming TEVT } \\
\text { (Vocational Training) }\end{array}$ & \multicolumn{2}{|c|}{ Accelerating labour reform } \\
\hline \multirow{2}{*}{\multicolumn{3}{|c|}{$\begin{array}{l}\text { Holding schools accountable for } \\
\text { outcomes }\end{array}$}} & & \multicolumn{2}{|c|}{$\begin{array}{l}\text { Attracting and retaining top } \\
\text { talent }\end{array}$} \\
\hline & & & Enhancing the competency & & \\
\hline \multicolumn{3}{|c|}{$\begin{array}{l}\text { Investing in great leaders for } \\
\text { schools }\end{array}$} & of tertiary graduates & \multicolumn{2}{|c|}{ Upgrading existing talent pool } \\
\hline \multicolumn{6}{|c|}{$\begin{array}{l}\text { Attracting and developing the best } \\
\text { teachers }\end{array}$} \\
\hline \multicolumn{3}{|c|}{$\begin{array}{l}\text { Revamping the education system } \\
\text { to significantly }\end{array}$} & Raising skills to increase & \multirow{2}{*}{\multicolumn{2}{|c|}{$\begin{array}{l}\text { Reforming thelabor market to } \\
\text { transform } \\
\text { Malaysia into a high-income } \\
\text { nation }\end{array}$}} \\
\hline raise studer & outcom & & employability & & \\
\hline
\end{tabular}

Source: Own work based on Economic Planning Unit, 2008.

The government of Malaysia seeks to improve the level and quality of human capital through enhancing the participation of youth. In 2009 the percentage of the population between 15-40 years stated for almost $42 \%$, which is indefinable for (European standards) and a chance to drive the country's development and push new reforms. What is official can be stated as: the need to „recognize the vital importance of youth in the economy. Therefore the Plan aims to better prepare them to undertake their roles in contributing towards national development, through instilling the right skills set, values and positive mindset to help them succeed. The youth population will need to be proactive and dynamic in 
order to adapt to the evolving landscape of the market economy." (The Tenth Malaysia Plan, 2010) Thus the program should focus on entrepreneurship and more investments in the R\&D field, as this could establish a competitive culture, lead to regional leadership and make a base to oppose the effects of global financial downturns while also extend the areas of potential growth. What could be done, except the investment in high-tech skills and monetary incentives, is to provide youth with the soft skills to interact and understand other ways of making decisions. Such combined skills will give the youth ability to interact in multi-linked economy and prevent further results of „trust leverage”. (The term „trust leverage" has been introduced by the author for the explanatory purposes in the framework of New Institutional Economics and New Economy).

Although there are other ,social" sectors of the economy to be improved upon and face a new dimension of challenges, the author is obliged to mention the following in order to show the need of institutional change in Malaysia and how it could sustain economic and financial downturns by providing a social safety net as well as the following:

- Ensuring the well-being of children,

- Supporting older persons and fulfilling their societal roles,

- Integrating disabled people into society,

- Strengthening the institution of family.

Through economic participation and bringing balance into the society, one has to emphasize the ability to overcome accepted roles and the need for cultural changes to face new (global) challenges imposed by the recent global financial crisis.

\section{Conclusion}

Institutional change and the new dimension of challenges visible after the global financial crisis give Malaysia a chance to reconstruct their socioeconomic framework and their main objectives. However, it cannot be continued unless a dramatic change is undertaken by the government. One has to look at the already given possibilities of retaining the effects of the crisis. While the ethnic diversity brings unequal chances, it does provide a more skilled and better prepared Malaysian to face the need of change. In Malaysia any formal change is up to the role played by the informal institutions. As the regional responsibility sheds its light on the transparency and need for new forms of investments, one should take a look at the example of Islamic financial institutions for which Malaysia is a hub, connecting Arab World with the rest of the Muslim countries. Any increase in asset value is an effect of the attitude of the people. Thus, trust and social acceptance as well as to fulfill one's desires to follow some religious norms bring about confidence into the „conventional” Islamic financial system. 
In this short article the author has tried to point out the hot spots for necessary institutional changes in Malaysia. As the term of financial crisis has been discussed among the leaders of ASEAN one can perceive indispensable changes on a social base. In regards to the 10th Malaysia Plan, it is also distressing that the government does not pay enough attention to the reasons for the slower than expected rate of economic development.

\section{References}

Cyberjaya (2012). Welcoming Newcomers, (2012). URL: <http://cyberview.com.my/v4/download/ Cyberjaya-e-Info-Vol-1-2012-(10Aug).pdf> [accessed September 30, 2012].

Hezri,Adnan. (2011). 'Sustainable Shift: Institutional challenges for the Environment in Malaysia'.Anjakan Kelestarian, Akademika 81 (2): 59-69. URL: <http://www.ukm.my/penerbit/akademika/ ACROBATAKADEMIKA81-2/81(2)Chap6-locked.pdf> [accessed September 30, 2012].

Institute of Strategic and International Studies (ISIS) and Universiti Malaya (2009). Human Development and Social Safety Nets, The Global Financial Crisis and the Malaysian Economy: Impact and responses. A Joint Report Commissioned by the United Nations Development Program (UNDP): 43.

Khalid, Fazlun. (2002). 'Islam and Environment' [in:] Timmerman P., Encyclopedia of Global Environmental Change, United Kingdom, (p. 3), URL: <http://www.ifees.org/islamenviroment. pdf $>$ [accessed September 30, 2012].

Kunio, Yoshihara. (2004). 'The Comparative Economic Performance in Malaysia', Southeast Asian Studies, Vol. 42, No. 1, June, URL: <http://repository.kulib.kyoto-u.ac.jp/dspace/bitstream/2433/53784/1/KJ00000692187.pdf > [accessed September 30, 2012].

Malaysian Rating Corporation Berhad. (2010). 'New Economic Model - Towards Realising Vision 2020'. (19): 130.

Ngah, Ibrahim and Tsong, TehBor. (2011). 'Low Carbon Lifestyle: A key in Moving Iskandar Malaysia Towards Low Carbon Region'. URL: <http://www.academia.edu/1132027> [accessed September 30, 2012].

The Tenth Malaysia Plan. (2010). 'Empowering Woman to Enhance Their Economic Contribution', Malaysia.

The Tenth Malaysia Plan. (2010). 'Moulding Youth to Become Dynamic and Inspired Future Leaders', Malaysia. 